\title{
Prognostic Significance of Cyclins A2, B1, D1, and E1 and CCND1 Numerical Aberrations in Oral Squamous Cell Carcinomas
}

\author{
Luís Silva Monteiro $\mathbb{D}^{1},{ }^{1}$ Márcio Diniz-Freitas, ${ }^{2}$ Saman Warnakulasuriya, ${ }^{3}$ \\ Tomás Garcia-Caballero, ${ }^{4}$ Jerónimo Forteza-Vila, $^{5}$ and Máximo Fraga ${ }^{6}$ \\ ${ }^{1}$ Institute of Research and Advanced Training in Health Sciences and Technologies (IINFACTS), University Institute of Health \\ Sciences (IUCS), CESPU, CP 4585-116 Paredes, Portugal \\ ${ }^{2}$ Medical-Surgical Dentistry Research Group (OMEQUI), Health Research Institute of Santiago de Compostela (IDIS), University of \\ Santiago de Compostela, CP 15782 Santiago, Spain \\ ${ }^{3}$ Oral Medicine Department, The Dental Institute, King's College and the WHO Collaborating Centre for Oral Cancer, \\ London SE5 9RW, UK \\ ${ }^{4}$ Morphological Sciences Department, School of Medicine, University Clinical Hospital, University of Santiago de Compostela, \\ CP 15782 Santiago, Spain \\ ${ }^{5}$ Instituto Valenciano de Patología, Universidad Católica de Valencia y Área Mixta de Investigación Oncológica (Centro de \\ Investigación Príncipe de Valencia-UCV), CP 46012 Valencia, Spain \\ ${ }^{6}$ Pathology Department, School of Medicine-University Clinical Hospital, University of Santiago de Compostela, \\ CP 15706 Santiago, Spain
}

Correspondence should be addressed to Luís Silva Monteiro; lmonteiro.md@gmail.com

Received 28 September 2017; Revised 31 December 2017; Accepted 17 January 2018; Published 27 March 2018

Academic Editor: Giovanni Tuccari

Copyright (c) 2018 Luís Silva Monteiro et al. This is an open access article distributed under the Creative Commons Attribution License, which permits unrestricted use, distribution, and reproduction in any medium, provided the original work is properly cited.

\begin{abstract}
We analysed the expression of cyclins A2, B1, D1, and E1 by immunohistochemistry and numerical aberrations in CCND1 gene by fluorescence in situ hybridization technique in 67 primary oral squamous cell carcinomas (OSCC). Cyclin A2 expression was observed in 54 (83.1\%) tumours, cyclin D1 in 58 (89.2\%), cyclin B1 in $39(60 \%)$, and cyclin E in 21 (32.8\%). CCND1 region analysis revealed $26(43.3 \%)$ tumours with the presence of numerical aberrations which were correlated with cyclin D1 high expression $(\mathrm{Rho}=0.48 ; p<0.001)$. Twenty-nine $(45.3 \%)$ tumours were classified as high proliferative tumours assessed by Ki-67 protein expression and correlated with tumours with high expression of cyclin A2 (Rho $=0.30 ; p=0.016)$ and cyclin B1 $(\mathrm{Rho}=0.37 ; p=0.003)$. In multivariate analysis for an overall five-year survival (OS), we found an adverse independent prognostic value for cyclin A2 high expression $(p=0.031)$ and for advanced tumour stage $(p<0.001)$. Our results confirm that several cyclins are commonly expressed in OSCC. CCND1 gene is abnormal in more than one-third of the cases and is frequently associated with cyclin D1 high expression. Moreover, cyclin A2 high expression is an independent indicator of worse OS suggesting that this protein may serve as a reliable biological marker to identify high-risk subgroups with poor prognosis.
\end{abstract}

\section{Introduction}

Oral cancer remains a significant cause of morbidity and mortality, with 529,451 new cases and 292,289 estimated deaths annually worldwide in 2012 [1]. Over 90 percent of cancers of the oral cavity are represented by oral squamous cell carcinomas (OSCC). Despite technological advances in the detection and management of oral cancer during the last few decades, many centres still report low survival rates $(\sim 50 \%)[2]$.

It is believed that oral carcinogenesis involves a series of genetic alterations that frequently involve normal cell cycle control proteins such as cyclins and their enzymatically active partners, the cyclin-dependent kinases (CDK) $[3,4]$. The discovery of major proteins involved in these alterations could identify new molecular markers that may serve as 
prognostic markers of OSCC and help in developing more precise treatment plans for these cancers $[3,5]$.

Cyclins are divided into two groups based on their function: the $\mathrm{G} 1$ cyclins $(\mathrm{C}, \mathrm{D}$, and $\mathrm{E})$, regulating the passage of cells through the G1 phase and their entry into the $S$ phase, and the mitotic cyclins (A, B) $[3,6]$. The CCND1 is a proto-oncogene located in chromosome 11q13 that encodes cyclin D1. This protein binds and activates CDK4 and CDK6, leading to phosphorylation of $\mathrm{pRb}$ driving the cell cycle from the G1 to the S phase. CCND1 amplification and overexpression have been reported to be frequent events in several tumours including head and neck cancers $[7,8]$. Several studies have reported the correlation between cyclin D1 overexpression and CCND1 amplification, lymph node metastasis, local recurrence, advanced histological grade (G2/G3), and poor survival $[9,10]$. Cyclin A is required for DNA synthesis during the $S$ phase and progression through the G2/M transition. Cyclin A overexpression has been found to be an adverse prognostic factor in oral premalignant and malignant lesions $[6,11,12]$. Cyclin $\mathrm{E}$ is expressed in the middle of the G1 phase and ends at the beginning of the $S$ phase. High levels of cyclin E1 may lead to accelerated G1/S transition and in an elongated $S$ phase duration, resulting in an increased chromosomal instability [13]. Overexpression of cyclin E1 has been reported in several cancers including nasopharyngeal carcinomas with an influence on prognosis [14]. Cyclin B1 is crucial to drive epithelial cells into the mitosis phase. Uncontrolled cyclin B1 expression may result in premature entry into mitosis, abnormal cell proliferation, and neoplastic transformation. Cytoplasmic overexpression of cyclin B1 has been reported in several cancers including head and neck cancers and is related with advanced histological grade and local recurrence of these cancers [15].

The aim of the current study was to evaluate the expression of cyclins A2, B1, D1, and E1 and CCND1 gene status in a single cohort of patients with oral squamous cell carcinomas (OSCC) and relate them to clinical-pathologic characteristics and patient outcome.

\section{Patients and Methods}

2.1. Patient Population. In this observational study, we included 67 patients newly diagnosed and treated for primary OSCC (ICD: C01-06) at the Clinical University Hospital of Santiago de Compostela (CUHSC) (Spain), between 1995 and 2003. The study was undertaken following the approval of the institutional ethical board of the hospital and performed in accordance with the Declaration of Helsinki. We followed the methods of Monteiro et al. [16]. Briefly, clinical information was obtained from the patient's records, including gender, age of the patient, tumour site, stage classification (7th edition of American Joint Committee on Cancer) [17], treatment performed (Table 1), surgical margin status, and follow-up information. On a new $4 \mu \mathrm{m}$ hematoxylin-eosin (HE) section, we revaluated histological diagnosis, tumour differentiation grade (WHO 2005) [18], and the presence of vascular or perineural invasion (Table 1).
TABle 1: Patient characteristics $(N=67)$.

\begin{tabular}{|c|c|c|}
\hline Factor & Group & $N(\%)$ \\
\hline \multirow{2}{*}{ Gender } & Female & $15(22.4 \%)$ \\
\hline & Male & $52(77.6 \%)$ \\
\hline \multirow{2}{*}{ Age (mean age: $59 \pm 12.6$ years) } & $<59$ years & $33(49.3 \%)$ \\
\hline & $\geq 59$ years & $34(50.7 \%)$ \\
\hline \multirow{6}{*}{ Location } & Tongue & $28(41.8 \%)$ \\
\hline & Floor of the mouth & $20(29.9 \%)$ \\
\hline & Gingiva & $7(10.4 \%)$ \\
\hline & Retromolar trigone & $4(6.0 \%)$ \\
\hline & Hard palate & $5(7.5 \%)$ \\
\hline & Buccal mucosa & $3(4.5 \%)$ \\
\hline \multirow{4}{*}{ Tumour size } & $\mathrm{T} 1$ & $22(32.8 \%)$ \\
\hline & $\mathrm{T} 2$ & $27(40.3 \%)$ \\
\hline & $\mathrm{T} 3$ & $6(9.0 \%)$ \\
\hline & $\mathrm{T} 4$ & $12(17.9 \%)$ \\
\hline \multirow{3}{*}{$\mathrm{N}$ status } & N0 & $46(68.7 \%)$ \\
\hline & $\mathrm{N} 1$ & $11(16.4 \%)$ \\
\hline & $\mathrm{N} 2$ & $10(14.9 \%)$ \\
\hline \multirow{4}{*}{ Stage } & I & $21(31.3 \%)$ \\
\hline & II & $20(29.9 \%)$ \\
\hline & III & $11(16.4 \%)$ \\
\hline & IV & $15(22.4 \%)$ \\
\hline \multirow{2}{*}{ Treatment* } & SG & $49(73.1 \%)$ \\
\hline & $\mathrm{SG}+\mathrm{RT}$ & $18(26.9 \%)$ \\
\hline \multirow{3}{*}{ Tumour grade } & G1 & $34(50.7 \%)$ \\
\hline & G2 & $29(43.3 \%)$ \\
\hline & G3 & $4(6 \%)$ \\
\hline \multirow{2}{*}{ Margin status** } & Free of tumour & $54(85.7 \%)$ \\
\hline & With tumour & $9(14.3 \%)$ \\
\hline \multirow{2}{*}{ Vascular invasion } & Absent & $62(92.5 \%)$ \\
\hline & Present & $5(7.5 \%)$ \\
\hline \multirow{2}{*}{ Perineural permeation } & Absent & $56(83.6 \%)$ \\
\hline & Present & $11(16.4 \%)$ \\
\hline
\end{tabular}

SG: surgery; RT: radiotherapy (consisting in adjunctive external-beam radiotherapy, 55-66Gy). *Patients were excluded if they had undergone radiotherapy or chemotherapy prior to surgery. None of the included patients received molecular therapies against EGFR or other proteins. ${ }^{* *}$ Not available in 4 cases. Table 1 is reproduced from Monteiro et al. [16] (under the Creative Commons Attribution License/Public Domain).

2.2. Immunohistochemistry. The immunohistochemical techniques were performed on tissue microarrays (TMA), constructed according to a previously described method $[16,19]$. For this, two cores $(1.5 \mathrm{~mm}$ each) from previously selected tumoural areas of each patient were used resulting in three TMA blocks with 134 cores.

For immunohistochemical staining, $4 \mu \mathrm{m}$ sections from TMA blocks were used. After deparaffinization and rehydration, slides were treated for antigen retrieval and incubated with the primary antibodies listed in Table 2. Visualization was performed using the dextran-polymer system (EnVisionTM Detection Kit, Dako, Glostrup, Demark) and 
TABle 2: Primary antibodies used in the present study.

\begin{tabular}{lcccc}
\hline Antibody & Clone & Dilution & Pretreatment & Manufacturer \\
\hline Anti-Ki-67 & MIB-1 & $1 / 200$ & WB + TE & DakoCytomation, Glostrup, Denmark \\
Anti-cyclin D1 & SP4 & Prediluted & WB & Master Diagnostica, Spain \\
Anti-cyclin E1 & $13 \mathrm{~A} 3$ & $1 / 50$ & WB & Novocastra Leica Biosystems, Newcastle upon Tyne, UK \\
Anti-cyclin A2 & $6 \mathrm{E} 6$ & $1 / 10$ & WB & Novocastra Leica Biosystems, Newcastle upon Tyne, UK \\
Anti-cyclin B1 & 7A9 & $1 / 10$ & WB & Novocastra Leica Biosystems, Newcastle upon Tyne, UK \\
\hline
\end{tabular}

WB: waterbath at $98^{\circ} \mathrm{C} 30$ minutes; TE: tris-ethylenediaminetetraacetic acid (EDTA).

counterstaining with Harris hematoxylin for $2 \mathrm{~min}$. For each staining run, we used positive (tonsil) and negative (omission of primary antibody) controls.

\subsection{Evaluation of Immunohistochemistry Expression. Two} observers (L.M. and M.F.) analysed the immunohistochemically stained slides using an Olympus BX41 microscope, blinded to the clinical characteristics of the tumours. Any discordant case was reviewed under a multihead microscope to achieve a final result. We considered the highest score of the two core disks.

The expression of cyclins was semiquantitatively evaluated on the basis of the extent of nuclear tumour cell staining for cyclin A2, cyclin D1, and cyclin E and cytoplasm tumour cell staining for cyclin B1. This expression was classified on a four-point score: negative (no labelling or labelling in $<10 \%$ of tumour cells); $1+$ (labelling in $10 \%$ to $24 \%$ of tumour cells); $2+$ labelling in $25 \%$ to $49 \%$ of tumour cells); and $3+$ (labelling in $50 \%$ or more of tumour cells). In the following high expression, thresholds were used as cut-offs: $25 \%$ for cyclin A2, 50\% for cyclin D1, and 10\% for cyclin B1 and cyclin E1. These cut-offs were determined for each cyclin based on the mean of the expression score for each marker (high value than the mean score was considered high expression) (adapted from Sawair et al. [20]). In this way, a score of $2+13+$ was considered as a high expression for cyclin A2 (mean score of $1.4 \pm 0.9$ ), a score of $3+$ for cyclin D1 (mean score of $2.3 \pm 1.1$ ), and any score of $1+/ 2+/ 3+$ for cyclin E1 (mean score of $0.8 \pm 0.7$ ) and cyclin B1(mean score of $0.4 \pm 0.7)$.

For Ki-67 evaluation, we considered two groups based on nuclear staining of tumour cells: low proliferative tumour (labelling from 0 to $49 \%$ of tumour cells) and high proliferative tumour (labelling in $50 \%$ or more of tumour cells) [21].

2.4. Fluorescence In Situ Hybridization. The detection of 11q13 band was carried out by fluorescence in situ hybridization technique. Briefly, the procedure was as follows:

Slides were dried overnight at $55^{\circ} \mathrm{C}$ for 20 minutes. After deparaffinization and rehydration, the slides were placed in saline sodium citrate (SSC2x) wash for 3 minutes in a water bath. Paraffin-embedded sample pretreatment was carried out with a sodium thiocyanate (NaSCN) $1 \mathrm{M}$, at $80^{\circ} \mathrm{C}$ for 30 minutes. Afterwards, the slides were placed in distilled water for 1 minute and in SSC $2 x$ for 5 minutes.
To perform the enzymatic digestion protocol, we used $0.05 \mathrm{mg} / \mathrm{mL}$ pepsin solution in $\mathrm{HCl} 0.01 \mathrm{~N}$. Enzyme activity for the various sections taken from each specimen was stopped at different times by slide immersion in SSC2x for 1 minute and tissue drying in a thermal plate at $45^{\circ} \mathrm{C}$. Tissue appearance was then observed under light microscopy with $10 \mathrm{x}$ and $40 \mathrm{x}$ magnification. Optimal tissue digestion was achieved when the tissue showed fern-like formations under light microscopy. After this, the slides were placed in 2 baths of SSC $2 x$ for 3 minutes and dehydrated. Then the slides were air dried at room temperature for 15 minutes.

Probe mix was carried out according to the manufacturer's specifications using the probe CCND1 FISH DNA Probe Split signal (Y5414) (DakoCytomation, Glostrup, Denmark). Hybridization was performed on the DakoCytomation Hybridizer (DakoCytomation Glostrup, Denmark), first at $84^{\circ} \mathrm{C}$ for 5 minutes and finally at $37^{\circ} \mathrm{C}$ overnight. For posthybridization washes, we used SSC $0.4 \mathrm{x}$ with $0.3 \%$ Nonidet P-40 (NP-40) at $73^{\circ} \mathrm{C}$ for 3 minutes. Then the slides were placed in SSC2x with $0.1 \% \mathrm{NP}-40$ at room temperature. Afterwards, the slides were air dried for 20 minutes and mounted in DAPI II ( $4^{\prime}-6^{\prime}$-diamidino-2-feniloide) counterstain from Vysis Inc. (Downers Grove, IL).

2.5. Evaluation of Fluorescence In Situ Hybridization. Image analysis was performed using an Eclipse E400 Nikon fluorescence microscope (Nikon, Tokyo, Japan) equipped with DAPI (nuclei) and Spectrum Green/Spectrum Orange dual band pass filter sets (magnification of 400x). We considered the presence of CCND1 numerical aberrations when at least $20 \%$ of the nuclei exhibited 3 or more signals for CCND1 in high-power fields [22].

2.6. Statistical Analysis. Possible relations between categorical variables were analysed using chi-square tests. The correlation between protein markers was measured by Spearman's correlation coefficient. Time interval (expressed in months) between primary treatment and last follow-up or death of the patient corresponded to overall survival (OS). Time interval (expressed in months) between primary treatment and the first recurrence (whether local, regional or distant) corresponded to disease-free survival (DFS). Univariate analysis of the influence of markers on five-year OS and DFS was performed using the Kaplan-Meier and the log-rank test. Factors that were significant in the univariate analysis were then analysed by multivariate analysis using the Cox proportional hazards model. 
The level of statistical significance was considered at $p<0.05$.

\section{Results}

3.1. Cyclin A2. Of the 134 cores of the cyclin A2 slides, 13 $(9.70 \%)$ cores could not be analysed: 8 (5.97\%) cores contained no tumour cells, 4 (2.99\%) were lost, and 1 (0.75\%) had not sufficient cells for scoring. In the view of this, 2 (2.99\%) out of 67 cases could not be analysed for cyclin A2.

The cyclin A2 expression was observed in $54(83.1 \%)$ cases (Figures 1(a) and 1(b)), classified as $1+$ in $29(44.6 \%)$, $2+$ in $15(23.1 \%)$, and $3+$ in $10(15.4 \%)$.

3.2. Cyclin B1. Out of 134 core disks, $10(7.46 \%)$ cores could not be evaluated for cyclin B1: 8 (5.97\%) contained no tumour cells, $1(0.75 \%)$ was lost during processing, and $1(0.75 \%)$ had not sufficient cells for scoring, resulting the elimination of $2(2.99 \%)$ cases.

The cyclin B1 expression was observed in 39 (60\%) cases (Figures 1(c) and 1(d)), classified as $1+$ in 29 $(44.6 \%)$ and $2+$ in $10(15.4 \%)$.

3.3. Cyclin D1. Out of 134 core disks, $10(7.46 \%)$ cores could not be analysed for cyclin D1: 8 (5.97\%) contained no tumour cells, $1(0.75 \%)$ was lost during processing, and $1(0.75 \%)$ had not sufficient cells for scoring resulting the elimination of $2(2.99 \%)$ cases.

The cyclin D1 expression was observed in $58(89.2 \%)$ cases (Figures 1(e) and 1(f)), classified as 1+ in $6(9.2 \%)$, $2+$ in $13(20 \%)$, and $3+$ in $39(60 \%)$.

3.4. Cyclin E1. Out of 134 core disks for cyclin E1, 13 (9.7\%) cores could not be analysed: $9(6.72 \%)$ contained no tumour cells, $3(2.24 \%)$ were lost during processing, and $1(0.75 \%)$ had not sufficient cells for scoring. Therefore, 3 (4.48\%) out of 67 cases could not be analysed for cyclin E1.

The cyclin E1 expression was positive in 21 (32.8\%) cases (Figures $1(\mathrm{~g})$ and $1(\mathrm{~h})$ ), classified as $1+$ in 15(23.4\%) and $2+$ in $6(9.4 \%)$.

3.5. Ki-67. In tissue microarray slides stained for Ki-67, 12 (8.96\%) cores could not be evaluated: 7 (5.22\%) contained no tumour cells, $4(2.99 \%)$ had too few cells for scoring, and $1(0.75 \%)$ was lost during processing. Because of this, 3 cases (4.47\%) could not be analysed at all.

Ki-67 expression was detected in almost all cases (61, 95.3\%) except in three. Twenty-nine (45.3\%) cases were classified as high proliferative tumours and 35 (54.7\%) as low proliferative tumours (Figures 1(i) and 1(j)).

3.6. CCND1 Gene Analysis. Out of 134 core disks, 14 (10.4\%) could not be evaluated for CCND1 analysis: 8 (5.97\%) contained no tumour cells and $6(4.5 \%)$ were lost during processing. Therefore, 7 (10.5\%) out of 67 cases could not be analysed for CCND1 gene analysis.

In assessing the CCND1 gene, we found that $43.3 \%(n=26)$ of the cases showed the presence of numerical aberrations (Figures 1(k) and 1(l)). In 19 cases (31.7\%), there were more than six signals or cluster formations present per nuclei.
3.7. Association of High Expression of Markers with Clinicopathological Features. The presence of high expression of cyclin A2 (in $25 \%$ or more of tumour cells) was associated with male gender $(p=0.023)$, more advanced $\mathrm{T}$ category $(p=0.003)$, and/or more advanced tumour stage ( $p=0.002)$. The presence of high expression of Ki-67 was associated with more advanced T category $(p=0.003)$, with more advanced tumour stages $(p=0.006)$, and with the presence of vascular invasion $(p=0.016)$. All cases with vascular invasion were high proliferative tumours.

None of the other markers (cyclin B1, D1, or E1 and CCND1 gene status) were correlated with clinicopathological features.

3.8. Coexpression of Markers of the Study. High Ki-67 expression was observed in tumours with high expression of cyclin A2 $(\mathrm{Rho}=0.30 ; p=0.016)$ and cyclin B1 $(\mathrm{Rho}=0.37$; $p=0.003)$. High expression of cyclin A2 was correlated with high expression of cyclin B1 (Rho $=0.32 ; p=0.009)$.

Tumours with cyclin D1 high expression (in 50\% or more of tumour cells) reached a significant relationship with the existence of numerical aberrations ( $\mathrm{Rho}=0.48 ; p<0.001$ ).

3.9. Patients' Outcome. Patients were observed for a minimum of 3 years after treatment or until their death. During the follow-up period, 36 (53.7\%) had died of oral cancer. Overall survival rate at 5 years of follow-up was $49.4 \%$, and DFS was $34 \%$. In univariate analysis, T status $(p<0.001)$, $\mathrm{N}$ status $(p<0.001)$, clinical stage $(p<0.001)$, perineural permeation $(p=0.039)$, and cyclin A2 expression $(p=0.005)$ (Figure 2 ) were statistically correlated to OS (Table 3 ). The same was observed with reference to DFS for $\mathrm{T}$ status $(p<0.001), \mathrm{N}$ status $(p<0.001)$, clinical stage $(p<0.001)$, and tumour grade $(p=0.007)$ (Table 3$)$.

In multivariate analysis for OS, we only found an independent prognostic value for stage and cyclin $\mathrm{A} 2$ expression (Table 4$)$, where tumours with advanced stage $(p<0.001)$ and with high expression of cyclin A2 $(p=0.031)$ had lower OS (Table 4$)$. For DFS, advanced stage $(p<0.001)$ and histological differentiation grade $(p=0.006)$ presented adverse independent prognostic value in the multivariate analysis (Table 4).

\section{Discussion}

Deregulation and aberrations of cell cycle-related cyclins have been implicated in the tumour growth and progression of several cancers $[3,5]$. The understanding of these alterations in tumorigenesis may identify new proteins that may serve as important cancer diagnostic and prognostic indicators as well as potential targets for therapeutic approaches in patients with OSCC $[16,23]$. With this in mind, we conducted this study to evaluate the influence of the expression of the cyclins A2, B1, D1, and E1 and CCND1 gene status on clinical, pathologic, and prognostic characteristics of patients with OSCC.

Cyclins were highly expressed in the present cohort of OSCC. Cyclin D1 was present in almost $90 \%$ of the cases and highly expressed in $60 \%$ being the most detected cyclin 


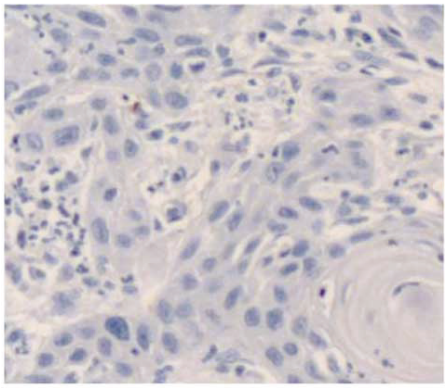

(a)

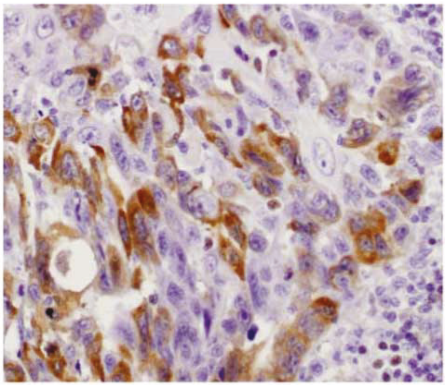

(d)

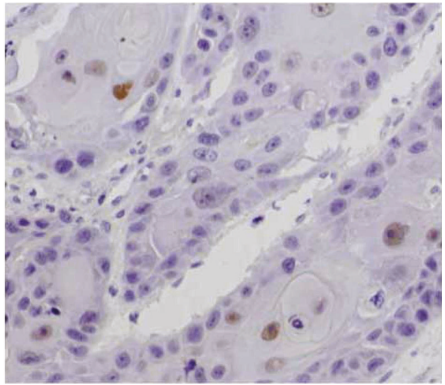

(g)

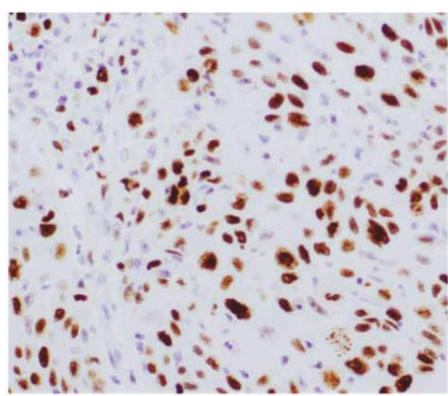

(j)

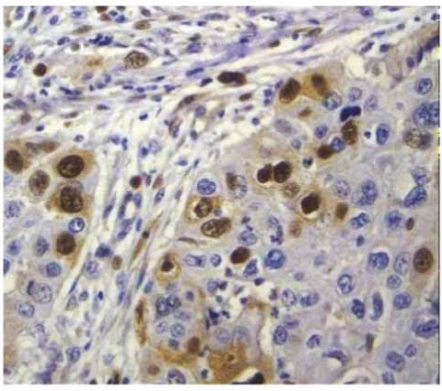

(b)

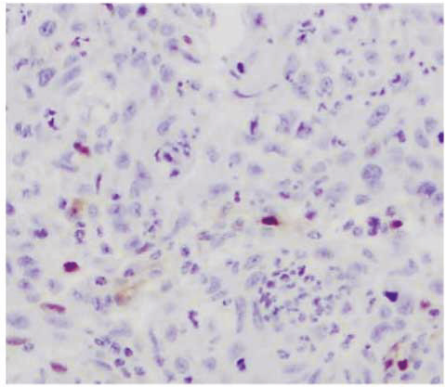

(e)

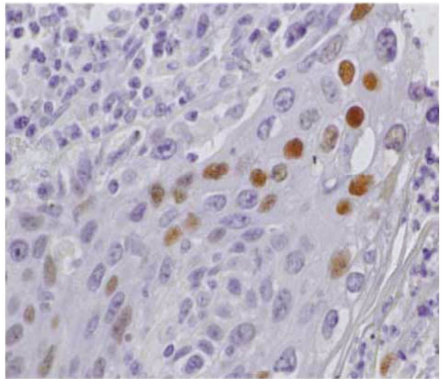

(h)

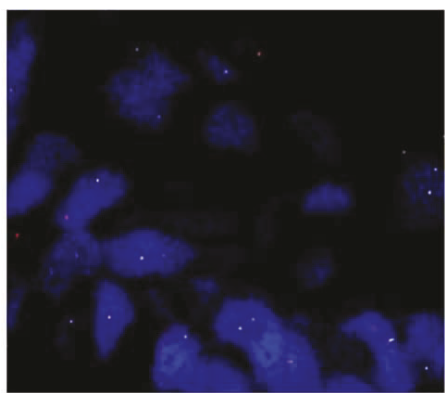

(k)

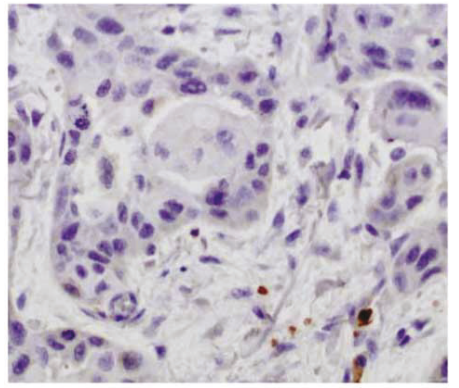

(c)

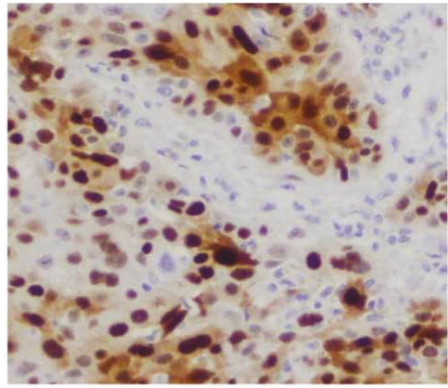

(f)

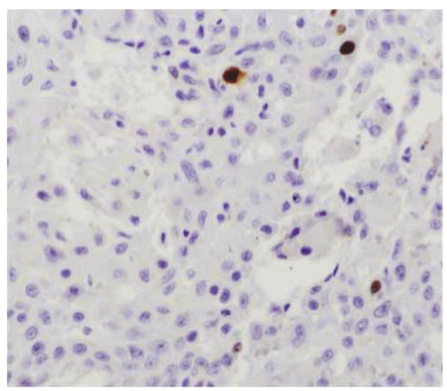

(i)

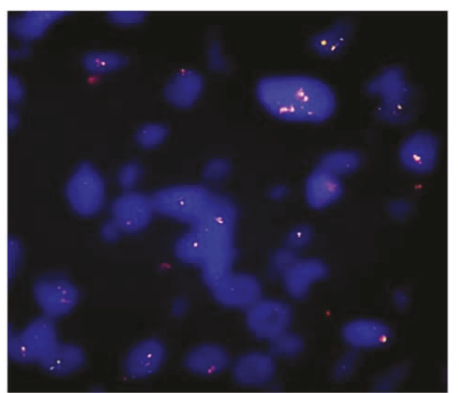

(1)

FIGURE 1: Immunohistochemical staining of cyclins and CCND1 region analysis by fluorescence in situ hybridization technique in OSCC. (a) Low expression for cyclin A2 (magnification $\times 200$ ). (b) High expression for cyclin A2 (magnification $\times 200)$. (c) Low expression for cyclin B1 (magnification $\times 200$ ). (d) High expression for cyclin B1 (magnification $\times 200)$. (e) Low expression for cyclin D1 (magnification $\times 200)$. (f) High expression for cyclin D1 (magnification $\times 200$ ). (g) Low expression for cyclin E1 (magnification $\times 200$ ). (h) High expression for cyclin E1 (magnification $\times 200$ ). (i) Low expression for Ki-67 (magnification $\times 200)$. (j) High expression for Ki-67 (magnification $\times 200)$. $(\mathrm{k})$ Normal CCND1 numerical signals (magnification $\times 200$ ). (l) Presence CCND1 numerical aberrations (magnification $\times 200)$.

in these tumours. This is in line with the reported high expression of this protein in OSCC $[8,21,24]$. High expression values were also noted for cyclin A2, observed in more than $80 \%$ of tumour cells, and lower frequencies were observed for cyclins B1 and E1. These levels of expression are in accordance with the reported literature for these proteins reflecting the relevant role of these proteins in OSCC $[6,11,13,25]$.

Several clinical and pathological indicators of the tumour progression, such as tumour size, nodal metastasis, clinical stage, and histological grade, have been related with cyclin expression. This is in accordance with the crucial 


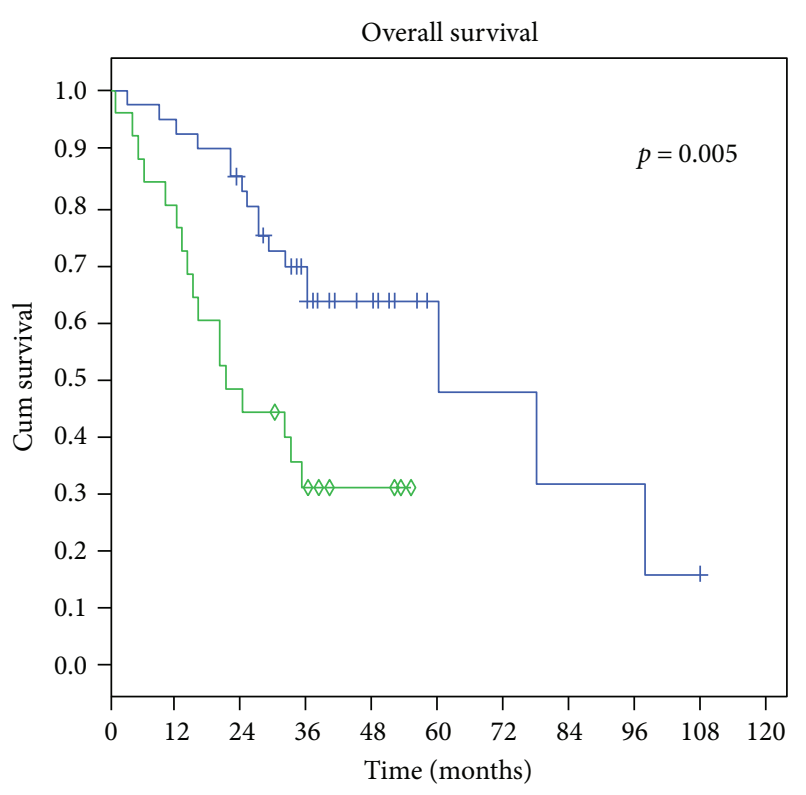

Cyclin A expression

$\begin{array}{ll}\neg \text { Low }(0-24 \%) & + \text { Low-censored } \\ \neg \text { High }(25-100 \%) & \diamond \text { High-censored }\end{array}$

Figure 2: Univariate Kaplan-Meier analysis of overall survival in patients with OSCC. Patients with tumours with high expression of cyclin A2 presented a lower survival rate than patients with low expression of cyclin A2.

contribution of cyclins in control of the cell cycle and thereby tumour proliferation $[6,11,22]$. We could confirm the associations of cyclin A2 with tumour size $(\mathrm{T})$, nodal metastasis, and the clinical stage suggesting that high expression of cyclin A2 could be relevant for tumour progression and metastization. Chen et al. [11] observed a significant association between high cyclin A2 expression and advanced stage tumour, advanced tumour size $(\mathrm{T})$, and presence of nodal metastasis. Saarilahti et al. [6] reported an association with histological grade.

To assess the relation of the expression of these cyclins with proliferative tumour phenotype, we evaluated the expression of the nuclear protein $\mathrm{Ki}-67$, a proliferation marker described in some studies as an indicator of aggressive behaviour serving as a prognostic indicator [21]. In the present work, high Ki-67 expression was detected in almost half of the cases and related with $\mathrm{T}$ and clinical stage and also with the presence of tumour vascular invasion. Interestingly, Ki-67 was significantly associated with the expression of cyclin A2 and cyclin B1 confirming the proliferative capacity of these tumour cells. Other authors have also observed this association between cyclin A2 and Ki-67 [6, 13, 26].

Cyclin D1 overexpression has been related with amplification of the CCND1 gene in several tumours including OSCC $[22,27,28]$. The activation of the pathways involved in cyclin D1 expression appears to be essential in the development of human cancers, including oral cancer [27]. In view of this, we analysed the status of the 11q13 region where this gene is located. We observed that $43.3 \%$ of the cases presented aberration of this region with 6 or more signals per cell in 32\% cases. Similar values were reported by other authors $[7,22,29]$ in head and neck cancer.

Furthermore, we observed a significant association of CCND1 status with cyclin D1 high expression. These results suggest that overexpression of cyclin D1 could be caused by numerical aberrations in the $11 \mathrm{q} 13$ region such as CCND1 amplification. Nevertheless, there were some cases with cyclin D1 high expression that presented a normal 11q13 status. This suggests that mechanisms other than amplification of CCND1 gene could be involved in overexpression of this cyclin including increasing mRNAs, decrease in cyclin D proteolytic degradation or DNA methylation [30, 31].

An important aspect of a molecular marker is the relation of the marker with the prognosis of the patient. We observed that OSCC patients with high expression of cyclin A2 in their cell tumours presented a significantly lower 5 -year overall survival even in multivariate survival analyses, indicating that cyclin A2 expression could be an independent prognostic marker in OSCC. Chen et al. [6], evaluating squamous cell carcinomas of the oral cavity, found an association between high cyclin A2 expression and lower overall survival. This was also seen in the study of Saarilahti et al. [11], in addition to the association with disease-free survival although in laryngeal carcinomas. Thomson et al. [32] observed an association of cyclin A expression with the recurrence of the disease in malignant and premalignant lesions of the oral cavity. Cyclin A is required for DNA synthesis during the $S$ phase and progression through the $\mathrm{G} 2 / \mathrm{M}$ transition. Our results suggest that tumours with cyclin A2 expression will drive the cells to division thus rendering them some growth potential. This will influence the survival/death of the tumour in patients with overexpression of this protein marker. In our series, no other cyclins or markers studied were significantly related with survival. Nevertheless, some studies reported the influence of other cyclins such as cyclin D1 $[8,10,22$, $29,30,33$ ] or cyclin B1 [25] on the prognosis of OSCC. Some recent papers have suggested the influence of CCND1 amplification on a poor overall survival and cervical nodal metastization which led us to evaluate not only the protein expression of cyclin A2 but also the CCND1 region status $[7,9,22]$. We could not find an association of numerical aberrations in the 11q13 region such as CCND1 amplification with any clinical and pathological variables such as nodal metastasis and also with survival. This could be due to the small size of our series, differences in tumour sites [7], or possible differences in geographic populations $[8,10]$. Our data indicate that for South European populations, cyclin A2 is a major prognostic marker, being an indicator of high proliferative status tumours but importantly also of a poor patient's survival with these tumours. This can assist oncologists in the planning treatment options for each patient with OSCC, indicating better and more adjusted chemotherapy or radiotherapy protocols considering the cyclin A2 status of the tumours $[34,35]$. Moreover, these proteins could function as targets for molecular therapies against this pathway leading to chronic mitotic arrest and cell death by apoptosis [36]. Our findings thus could have a translational value in the development of targeted therapies for OSCC [37]. 
TABLE 3: Univariate analysis of overall survival and disease-free survival at 5 years, according to clinicopathological characteristics and marker expression.

\begin{tabular}{|c|c|c|c|c|c|c|c|}
\hline Factor & Group & $N$ & Overall survival (5 years) & $p$ value & $N^{* *}$ & Disease-free survival (5 years) & $p$ value \\
\hline \multirow{2}{*}{ Gender } & Female & 15 & 64.2 & 0.206 & 14 & 50 & \multirow{2}{*}{0.442} \\
\hline & Male & 52 & 47.3 & & 50 & 30.7 & \\
\hline \multirow{2}{*}{ Age } & $<59$ years & 33 & 44.4 & 0.500 & 33 & 30.6 & \multirow{2}{*}{0.534} \\
\hline & $\geq 59$ years & 34 & 54.6 & & 31 & 39.6 & \\
\hline \multirow{6}{*}{ Location } & Tongue & 28 & 46.5 & \multirow{6}{*}{0.261} & 28 & 44.5 & \multirow{6}{*}{0.688} \\
\hline & Floor of the mouth & 20 & 44.4 & & 20 & 25 & \\
\hline & Gingiva & 7 & 28.6 & & 5 & 40 & \\
\hline & Retromolar trigone & 4 & 50 & & 3 & 33.3 & \\
\hline & Hard palate & 5 & 80 & & 5 & 20 & \\
\hline & Buccal mucosa & 3 & 0 & & 3 & 66.7 & \\
\hline \multirow{4}{*}{ Tumour size } & $\mathrm{T} 1$ & 22 & 71.5 & \multirow{4}{*}{$<0.001$} & 22 & 58.3 & \multirow{4}{*}{$<0.001$} \\
\hline & $\mathrm{T} 2$ & 27 & 53.2 & & 27 & 30.5 & \\
\hline & $\mathrm{T} 3$ & 6 & 33.3 & & 6 & 22.2 & \\
\hline & $\mathrm{T} 4$ & 12 & 8.3 & & 9 & 0 & \\
\hline \multirow{3}{*}{$\mathrm{N}$ status } & No & 46 & 68.2 & \multirow{3}{*}{$<0.001$} & 46 & 44.9 & \multirow{3}{*}{$<0.001$} \\
\hline & N1 & 11 & 9.1 & & 10 & 12 & \\
\hline & $\mathrm{N} 2$ & 10 & 10 & & 8 & 0 & \\
\hline \multirow{4}{*}{ Stage } & $\mathrm{I}$ & 21 & 74.9 & \multirow{4}{*}{$<0.001$} & 21 & 61.1 & \multirow{4}{*}{$<0.001$} \\
\hline & II & 20 & 67.8 & & 20 & 43.3 & \\
\hline & III & 11 & 27.3 & & 11 & 21.2 & \\
\hline & IV & 15 & 6.7 & & 12 & 0.0 & \\
\hline \multirow{2}{*}{ Treatment } & SG & 49 & 53.2 & \multirow{2}{*}{0.340} & 48 & 34 & \multirow{2}{*}{0.964} \\
\hline & $\mathrm{SG}+\mathrm{RT}$ & 18 & 38.9 & & 16 & 35.7 & \\
\hline \multirow{3}{*}{ Tumour histological grade } & G1 & 34 & 63.7 & \multirow{3}{*}{0.147} & 32 & 47.3 & \multirow{3}{*}{0.011} \\
\hline & G2 & 29 & 36.1 & & 28 & 27.2 & \\
\hline & G3 & 4 & 25 & & 4 & 0 & \\
\hline \multirow{2}{*}{ Margin status* } & Free of tumour & 54 & 51.9 & 0211 & 53 & 37.8 & 0757 \\
\hline & With tumour & 9 & 33.3 & 0.211 & 8 & 37.5 & 0.737 \\
\hline & Absent & 62 & 50.1 & & 59 & 33.9 & \\
\hline Vascular invasion & Present & 5 & 40 & 0.620 & 5 & 40 & 0.886 \\
\hline & Absent & 56 & 54 & 0.039 & 54 & 34.2 & 0.632 \\
\hline Perineural permeation & Present & 11 & 27.3 & 0.039 & 10 & 37.5 & 0.632 \\
\hline Cyclin A? & $<25 \%$ & 40 & 63.3 & 0005 & 40 & 43.8 & 0203 \\
\hline 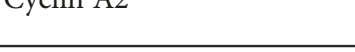 & $\geq 25 \%$ & 25 & 30.8 & 0.005 & 22 & 22.3 & 0.203 \\
\hline & $<10 \%$ & 26 & 57 & & 25 & 32 & \\
\hline Cyclin BI & $\geq 10 \%$ & 39 & 46.9 & 0.331 & 37 & 39.2 & 0.526 \\
\hline Cyclin D1 & $<50 \%$ & 26 & 60.6 & 0.172 & 24 & 49.4 & 0236 \\
\hline Cycill D & $\geq 50 \%$ & 39 & 44.8 & $0.1 / 2$ & 38 & 26.3 & 0.230 \\
\hline Cvclin F1 & $<10 \%$ & 43 & 48.2 & 0233 & 40 & 33.9 & \\
\hline Cycim L1 & $\geq 10 \%$ & 21 & 59.1 & 0.233 & 21 & 41.6 & 0.758 \\
\hline$V i$ & $<50 \%$ & 35 & 58.6 & & 35 & 38.1 & \\
\hline K1-6/ & $\geq 50 \%$ & 29 & 44.0 & 0.111 & 26 & 36.1 & 0.988 \\
\hline CCND1 & Normal & 34 & 52.3 & 0.991 & 32 & 40.2 & 0.412 \\
\hline CNDI & Numerical aberration & 26 & 47.1 & 0.991 & 25 & 29.7 & 0.412 \\
\hline
\end{tabular}

SG: surgery; RT: radiotherapy. ${ }^{*}$ Not available in 4 cases. ${ }^{* *}$ The number of patients in the disease-free survival in some of the analyses is different from the overall survival analysis as some patients had persistence of the disease and were only evaluated in the overall survival. 
TABLE 4: Variables included in the multivariate Cox regression analysis of overall survival and disease-free survival.

\begin{tabular}{|c|c|c|c|c|c|}
\hline Factor & Group & $\mathrm{N}$ & $p$ value & $\operatorname{Exp}(\beta)$ & $95 \% \mathrm{CI}$ of $\operatorname{Exp}(\beta)$ \\
\hline & & \multicolumn{4}{|c|}{ Overall survival } \\
\hline \multirow{4}{*}{ Tumour size } & $\mathrm{T} 1$ & 21 & 0.659 & 1 & \\
\hline & $\mathrm{T} 2$ & 27 & 0.263 & 0.223 & $0.016-3.08$ \\
\hline & $\mathrm{T} 3$ & 6 & 0.368 & 0.237 & $0.01-5.445$ \\
\hline & $\mathrm{T} 4$ & 11 & 0.217 & 0.220 & $0.2-2.437$ \\
\hline \multirow{3}{*}{ Nodal status } & N0 & 45 & 0.716 & 1 & \\
\hline & N1 & 11 & 0.466 & 1.672 & $0.42-6.658$ \\
\hline & $\mathrm{N} 2$ & 9 & 0.462 & 1.909 & $0.341-10.678$ \\
\hline \multirow{4}{*}{ Stage } & I & 20 & $<0.001$ & 1 & \\
\hline & II & 20 & 0.922 & 1.063 & $0.315-3.58$ \\
\hline & III & 11 & 0.041 & 3.548 & $1.052-11.963$ \\
\hline & IV & 14 & $<0.001$ & 14.309 & $4.641-44.121$ \\
\hline \multirow{2}{*}{ Perineural permeation } & Absent & 54 & 0.306 & 1 & \\
\hline & Present & 11 & & 1.654 & $0.631-4.339$ \\
\hline \multirow{2}{*}{ Cyclin A2 } & $<25 \%$ & 40 & 0.031 & 1 & \\
\hline & $\geq 25 \%$ & 25 & & 2.397 & $1.085-5.295$ \\
\hline \multirow{5}{*}{ Tumour size } & & \multicolumn{4}{|c|}{ Disease-free survival } \\
\hline & $\mathrm{T} 1$ & 22 & 0.407 & 1 & \\
\hline & $\mathrm{T} 2$ & 27 & 0.783 & 0.691 & $0.05-9.568$ \\
\hline & $\mathrm{T} 3$ & 6 & 0.426 & 0.281 & $0.012-6.396$ \\
\hline & $\mathrm{T} 4$ & 9 & 0.234 & 0.249 & $0.025-2.455$ \\
\hline \multirow{3}{*}{ Nodal status } & No & 46 & 0.484 & 1 & \\
\hline & N1 & 10 & 0.367 & 0.479 & $1.1-5.362$ \\
\hline & $\mathrm{N} 2$ & 8 & 0.232 & 0.313 & $1.821-19.42$ \\
\hline \multirow{4}{*}{ Stage } & $\mathrm{I}$ & 21 & $<0.001$ & 1 & \\
\hline & II & 20 & 0.232 & 1.741 & $0.7018-4.321$ \\
\hline & III & 11 & 0.054 & 2.666 & $0.982-7.237$ \\
\hline & IV & 12 & $<0.001$ & 9.767 & $3.727-25.599$ \\
\hline \multirow{3}{*}{ Histological grade } & G1 & 32 & 0.006 & 1 & \\
\hline & G2 & 28 & 0.028 & 2.428 & $1.100-5.362$ \\
\hline & G3 & 4 & 0.003 & 5.947 & $1.821-19.420$ \\
\hline
\end{tabular}

Variables included in multivariable Cox regression analysis for OS: tumour size, nodal status, clinical stage, perineural permeation, and cyclin A2 expression, and for DFS: tumour size, nodal status, clinical stage, and tumour histological grade.

Nevertheless, we wish to highlight some limitations of the present study, related with its retrospective nature that sometimes could not give the range of variables and information that prospective studies could give.

In conclusion, we report high expression of cell cycle-related proteins such as cyclin D1 and cyclin A2 in OSCC. Importantly, we found an independent prognostic value for cyclin A2 protein in OSCC indicating a poor overall survival for patients with tumours with high expression of cyclin A2. The present study suggests that this protein could serve as a prognostic marker in OSCC.

\section{Conflicts of Interest}

There are no potential conflicts of interest.

\section{Acknowledgments}

This study was supported by a grant from the Fundación de Investigación Médica Mutua Madrileña (Spain) and Instituto de Salud Carlos III (FIS PI 061902). The authors also thank the Biobanco del Complejo Hospitalario Universitario de Santiago and IINFACTS in CESPU (BubOral CESPU 2017; MacrOral CESPU 2017).

\section{References}

[1] L. A. Torre, F. Bray, R. L. Siegel, J. Ferlay, J. Lortet-Tieulent, and A. Jemal, "Global cancer statistics, 2012," CA: A Cancer Journal for Clinicians, vol. 65, no. 2, pp. 87-108, 2015.

[2] S. Warnakulasuriya, "Global epidemiology of oral and oropharyngeal cancer," Oral Oncology, vol. 45, no. 4-5, pp. 309-316, 2009. 
[3] W. C. Hahn and R. A. Weinberg, "Rules for making human tumor cells," The New England Journal of Medicine, vol. 347, no. 20, pp. 1593-1603, 2002.

[4] A. I. Goranov and A. Amon, "Growth and division-not a oneway road," Current Opinion in Cell Biology, vol. 22, no. 6, pp. 795-800, 2010.

[5] S. Schmitz and J. P. Machiels, "Molecular biology of squamous cell carcinoma of the head and neck: relevance and therapeutic implications," Expert Review of Anticancer Therapy, vol. 10, no. 9, pp. 1471-1484, 2010.

[6] K. Saarilahti, M. Kajanti, M. Kouri, L. M. Aaltonen, K. Franssila, and H. Joensuu, "Cyclin A and Ki-67 expression as predictors for locoregional recurrence and outcome in laryngeal cancer patients treated with surgery and postoperative radiotherapy," International Journal of Radiation Oncology, Biology, Physics, vol. 57, no. 4, pp. 986-995, 2003.

[7] H. Hanken, A. Gröbe, G. Cachovan et al., "CCND1 amplification and cyclin D1 immunohistochemical expression in head and neck squamous cell carcinomas," Clinical Oral Investigations, vol. 18, no. 1, pp. 269-276, 2014.

[8] S. F. Huang, S. D. Cheng, W. Y. Chuang et al., "Cyclin D1 overexpression and poor clinical outcomes in Taiwanese oral cavity squamous cell carcinoma," World Journal of Surgical Oncology, vol. 10, no. 1, p. 40, 2012.

[9] R. Noorlag, P. M. van Kempen, I. Stegeman, R. Koole, R. J. van Es, and S. M. Willems, "The diagnostic value of 11q13 amplification and protein expression in the detection of nodal metastasis from oral squamous cell carcinoma: a systematic review and meta-analysis," Virchows Archiv, vol. 466, no. 4, pp. 363-373, 2015.

[10] Y. Zhao, D. Yu, H. Li et al., "Cyclin D1 overexpression is associated with poor clinicopathological outcome and survival in oral squamous cell carcinoma in Asian populations: insights from a meta-analysis," PLoS One, vol. 9, no. 3, article e93210, 2014.

[11] H. M. Chen, M. Yen-Ping Kuo, K. H. Lin, C. Y. Lin, and C. P. Chiang, "Expression of cyclin A is related to progression of oral squamous cell carcinoma in Taiwan," Oral Oncology, vol. 39, no. 5, pp. 476-482, 2003.

[12] R. Tandon, L. L. Cunningham, D. K. White, A. S. Herford, and M. Cicciu, "Overexpression of cyclin A in oral dysplasia: an international comparison and literature review," Indian Journal of Cancer, vol. 51, no. 4, pp. 502-505, 2014.

[13] M. Fraczek, Z. Wozniak, D. Ramsey, T. Zatonski, and T. Krecicki, "Clinicopathologic significance and prognostic role of cyclin E and cyclin A expression in laryngeal epithelial lesions," Acta Oto-Laryngologica, vol. 128, no. 3, pp. 329-334, 2008.

[14] M. T. Ko, C. Y. Su, S. C. Huang, C. H. Chen, and C. F. Hwang, "Overexpression of cyclin $\mathrm{E}$ messenger ribonucleic acid in nasopharyngeal carcinoma correlates with poor prognosis," The Journal of Laryngology \& Otology, vol. 123, no. 09, pp. 1021-1026, 2009.

[15] T. K. Hoffmann, S. Trellakis, K. Okulicz et al., "Cyclin B1 expression and $p 53$ status in squamous cell carcinomas of the head and neck," Anticancer Research, vol. 31, no. 10, pp. 3151-3157, 2011.

[16] L. S. Monteiro, M. Diniz-Freitas, T. Garcia-Caballero, S. Warnakulasuriya, J. Forteza, and M. Fraga, "Combined cytoplasmic and membranous EGFR and p53 overexpression is a poor prognostic marker in early stage oral squamous cell carcinoma," Journal of Oral Pathology \& Medicine, vol. 41, no. 7, pp. 559-567, 2012.

[17] M. Brandwein-Gensler and R. V. Smith, "Prognostic indicators in head and neck oncology including the new 7th edition of the AJCC staging system," Head and Neck Pathology, vol. 4, no. 1, pp. 53-61, 2010.

[18] L. Barnes, J. W. Everson, P. Reichart, and D. Sidransky, World Health Organization Classification of Tumours: Pathology and Genetics of Head and Neck Tumours, IARC Press, Lyon, France, 2005.

[19] L. S. Monteiro, M. Diniz-Freitas, T. Garcia-Caballero, J. Forteza, and M. Fraga, "EGFR and Ki-67 expression in oral squamous cell carcinoma using tissue microarray technology," Journal of Oral Pathology \& Medicine, vol. 39, no. 7, pp. 571$578,2010$.

[20] F. Sawair, Y. Hassona, C. Irwin et al., "p53, cyclin D1, p21 (WAF1) and Ki-67 (MIB1) expression at invasive tumour fronts of oral squamous cell carcinomas and development of local recurrence," Asian Pacific Journal of Cancer Prevention, vol. 17, no. 3, pp. 1243-1249, 2016.

[21] J. Carlos de Vicente, A. Herrero-Zapatero, M. F. Fresno, and J. S. Lopez-Arranz, "Expression of cyclin D1 and Ki-67 in squamous cell carcinoma of the oral cavity: clinicopathological and prognostic significance," Oral Oncology, vol. 38, no. 3, pp. 301-308, 2002.

[22] N. Uzawa, I. Sonoda, K. Myo, K. Takahashi, R. Miyamoto, and T. Amagasa, "Fluorescence in situ hybridization for detecting genomic alterations of cyclin D1 and p16 in oral squamous cell carcinomas," Cancer, vol. 110, no. 10, pp. 2230-2239, 2007.

[23] R. Mishra, "Cell cycle-regulatory cyclins and their deregulation in oral cancer," Oral Oncology, vol. 49, no. 6, pp. 475-481, 2013.

[24] M. Y. Kuo, C. Y. Lin, L. J. Hahn, S. J. Cheng, and C. P. Chiang, "Expression of cyclin D1 is correlated with poor prognosis in patients with areca quid chewing-related oral squamous cell carcinomas in Taiwan," Journal of Oral Pathology \& Medicine, vol. 28, no. 4, pp. 165-169, 1999.

[25] K. A. Hassan, K. K. Ang, A. K. El-Naggar et al., "Cyclin B1 overexpression and resistance to radiotherapy in head and neck squamous cell carcinoma," Cancer Research, vol. 62, no. 22, pp. 6414-6417, 2002.

[26] J. Kushner, G. Bradley, B. Young, and R. C. Jordan, “Aberrant expression of cyclin A and cyclin B1 proteins in oral carcinoma," Journal of Oral Pathology \& Medicine, vol. 28, no. 2, pp. 77-81, 1999.

[27] P. Ramos-García, J. A. Gil-Montoya, C. Scully et al., "An update on the implications of cyclin D1 in oral carcinogenesis," Oral Diseases, vol. 23, no. 7, pp. 897-912, 2017.

[28] R. Noorlag, K. Boeve, M. J. H. Witjes et al., “Amplification and protein overexpression of cyclin D1: predictor of occult nodal metastasis in early oral cancer," Head \& Neck, vol. 39, no. 2, pp. 326-333, 2017.

[29] K. Myo, N. Uzawa, R. Miyamoto, I. Sonoda, Y. Yuki, and T. Amagasa, "Cyclin D1 gene numerical aberration is a predictive marker for occult cervical lymph node metastasis in TNM stage I and II squamous cell carcinoma of the oral cavity," Cancer, vol. 104, no. 12, pp. 2709-2716, 2005.

[30] M. Masuda, M. Suzui, R. Yasumatu et al., "Constitutive activation of signal transducers and activators of transcription 3 correlates with cyclin D1 overexpression and may provide a novel prognostic marker in head and neck squamous cell 
carcinoma," Cancer Research, vol. 62, no. 12, pp. 3351-3355, 2002.

[31] L. M. Arantes, A. C. de Carvalho, M. E. Melendez et al., "Validation of methylation markers for diagnosis of oral cavity cancer," European Journal of Cancer, vol. 51, no. 5, pp. 632-641, 2015.

[32] P. J. Thomson, M. L. Goodson, C. Booth, N. Cragg, and O. Hamadah, "Cyclin A activity predicts clinical outcome in oral precancer and cancer," International Journal of Oral \& Maxillofacial Surgery, vol. 35, no. 11, pp. 1041-1046, 2006.

[33] A. Almangush, I. Heikkinen, A. A. Mäkitie et al., "Prognostic biomarkers for oral tongue squamous cell carcinoma: a systematic review and meta-analysis," British Journal of Cancer, vol. 117, no. 6, pp. 856-866, 2017.

[34] M. Rodriguez-Pinilla, J. L. Rodriguez-Peralto, R. Hitt et al., "Cyclin A as a predictive factor for chemotherapy response in advanced head and neck cancer," Clinical Cancer Research, vol. 10, no. 24, pp. 8486-8492, 2004.

[35] L. P. Zhong, D. W. Zhu, W. N. William Jr. et al., "Elevated cyclin D1 expression is predictive for a benefit from TPF induction chemotherapy in oral squamous cell carcinoma patients with advanced nodal disease," Molecular Cancer Therapeutics, vol. 12, no. 6, pp. 1112-1121, 2013.

[36] D. Maggioni, G. Nicolini, R. Rigolio et al., "Myricetin and naringenin inhibit human squamous cell carcinoma proliferation and migration in vitro," Nutrition and Cancer, vol. 66, no. 7, pp. 1257-1267, 2014.

[37] L. Monteiro and S. Warnakulasuriya, "Genetic aberrations and molecular pathways in head and neck cancer," in Squamous Cell Carcinoma, Molecular Therapeutic Targets, S. Warnakulasuriya and Z. Khan, Eds., pp. 97-111, Springer, Berlin, 2017. 


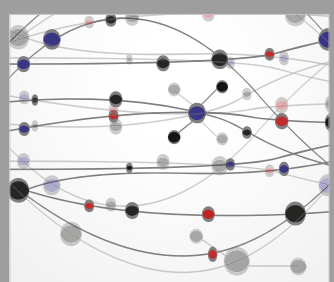

The Scientific World Journal
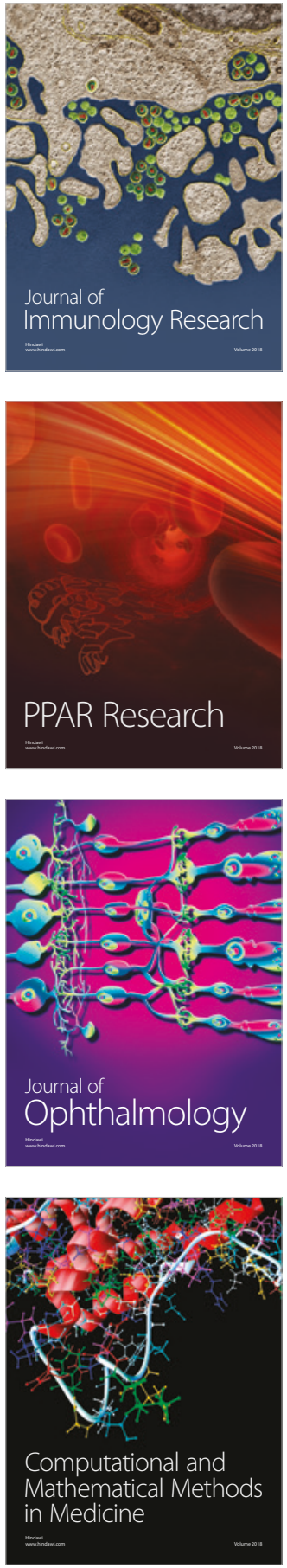

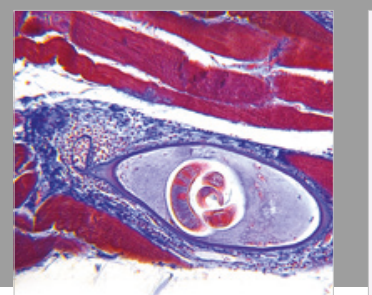

Gastroenterology Research and Practice

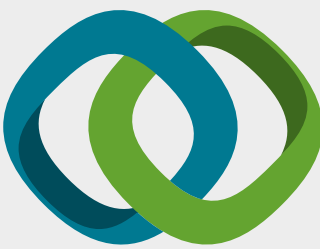

\section{Hindawi}

Submit your manuscripts at

www.hindawi.com
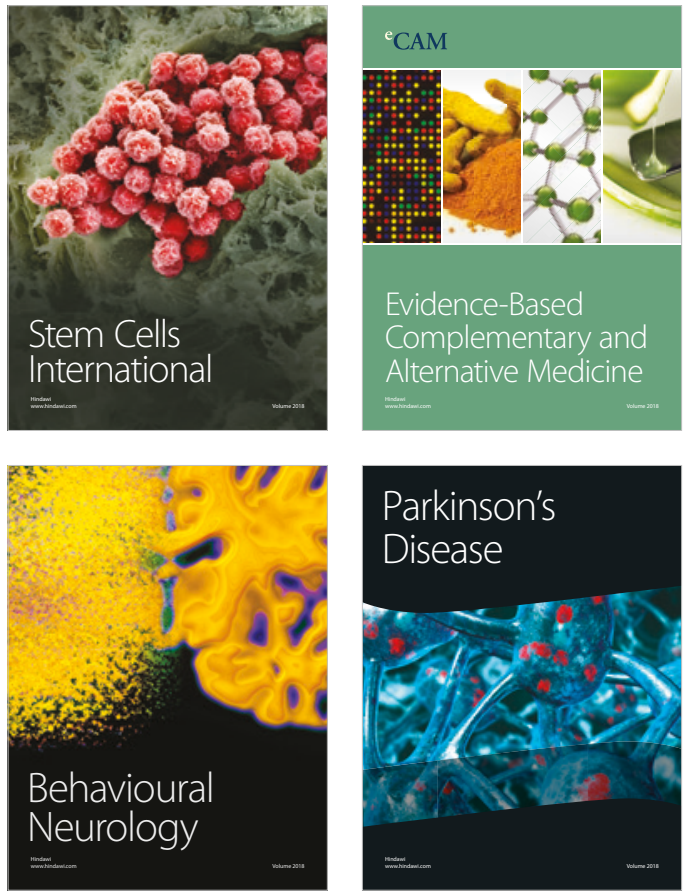

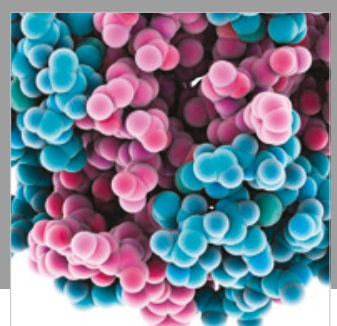

ournal of

Diabetes Research

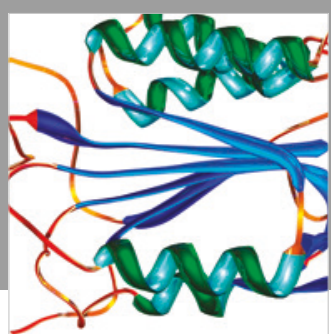

Disease Markers
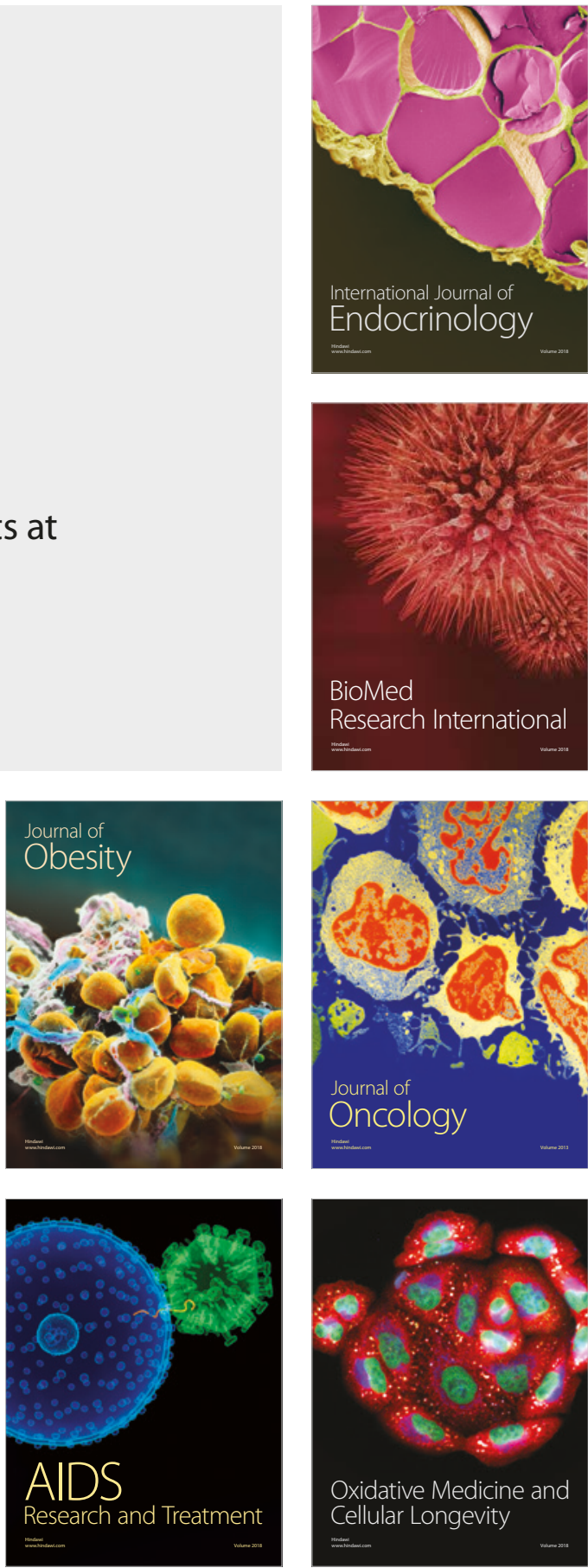